\title{
Interaction Between Coping Strategies Among Infertile Couples and Women's Psychological Symptoms
}

Ashraf Kazemi ( $\square$ Kazemi@nm.mui.ac.ir)

Isfahan University of Medical Sciences https://orcid.org/0000-0001-7182-0012

\section{Marjan Torabi}

Isfahan University of Medical Sciences

Mahshid Abdishahshahani

Isfahan University of Medical Sciences

\section{Research article}

Keywords: Coping strategy, Infertility, Psychological symptoms, Stress, Anxiety, Depression

Posted Date: April 24th, 2020

DOl: https://doi.org/10.21203/rs.3.rs-21323/v1

License: @ (i) This work is licensed under a Creative Commons Attribution 4.0 International License. Read Full License 


\section{Abstract}

Background Social problems and suffering from treatment process for infertile couples requires the couples use coping strategies for balancing the infertility crisis. According to the close interactions of the couples with each other, the objective of the study was assess of interrelationships between coping strategies of the infertile couples under assisted reproductive treatment and women's psychological symptoms.

Method This cross sectional research was done on 212 infertile couples undergoing assisted reproductive treatment. The using level of coping strategies, the stress, anxiety and depression levels were evaluated by using valid questionnaire. The relations between the coping strategies of the couples with each other, and also women's stress, anxiety and depression levels were evaluated.

Results The results showed the relationship between using the coping strategies by men, except understanding emotion, maintaining optimism strategies, and the coping strategies by women showed a significant relation. The results showed that the stress, anxiety and depression levels of women were positively related to the using of self-focused rumination and other blame strategies.

Conclusion The couples' coping strategies toward infertility are interacted and psychological symptoms in women's are affected by their partners' coping strategies and using of self-focused rumination and other blame strategies by men may effect on partners' psychological health.

\section{Background}

Infertility With the prevalence about $15 \%$ faces the couples with many social problems. Increasing the probability of domestic violence [1], divorce [2], Polygyny in some countries [3] and social isolation [4] will reduce the life quality of infertile couples [5]. Although using the methods of fertility assistance has had noticeable successes but the suffering from social stigma after infertility $[2,6]$, stress from treatment processes [7] and the costs of treatment and negative results of treatment in $65 \%$ of treatment cycles [8] have turned infertility into a crisis for the involved couples and will be accompanied by increasing stress, anxiety and depression [9]. Therefore, preventing the malignant effects requires balancing the crisis by using effective and efficient coping strategies.

Coping strategies are such processes that a person tries to manage crisis stresses by them. And they include any kinds of preventing coping strategies, focusing on the problem and on the emotions. The rational result of using them is to balance the destructive effect of crisis on people's psychological conditions. But in addition to individual and personal features, the type and severity of the crisis interfere in the impact factor of each coping strategy. It's believed that in the conditions of severe crisis, using emotional circuit strategies provides mental conditions for the people focusing on the problem. As the people also feel that they aren't able to control the conditions; using the coping strategies focused on emotions will have an important role for balancing the stresses from crises. For its sake, the crisis severity has effect on coping strategies so that according to a report, the thought of being uncontrollable treatment has been accompanied by using prevention coping strategies [10].

Studying the relation of coping strategies with psychological conditions of infertile couples has also showed that using the self-blame strategies makes increase in anxiety probability. While, some studies have shown that, using this strategy in infertile couples related with promotion of marital quality [11], life quality and also psychological health [12].

This difference in the effect of coping strategies on the psychological conditions of infertile couples points to the effects of such factors that provide the field for selecting the coping strategy. Accompanying infertility experience with infertility stigma and social suffering [6] and the importance of fertility dependent on the social context of Asian countries in keeping marital lives have turned infertility into a social problem [13].

Difference between social roles of men and women, especially in developing societies, has caused different social-mental conditions for men and women which can be accompanied by using different coping strategies in both genders. Although women are more vulnerable than men in confronting with infertility and they suffer more than men from psychological disorders [14] and its social problems; but affinity between the couples and their interaction and feeling exchange between them may impress each couple's coping strategies on the other and also psychological trauma from their infertility. Therefore, it's necessary to consider their interpersonal interactions for recognizing the relationship between coping strategies with psychological health in the infertile couples. Therefore, this study has been done in order to evaluate the coping strategies of infertile couples against the other's applied strategies and its relationship with the level of their psychological symptoms. 


\section{Methods}

This cross sectional study has been done on 212 couples under treatments of assisted reproductive treatment in Iran-Isfahan infertility center since January 2018 to May 2018.

The inclusion criteria to study included disusing of gamete or donated embryo, contemporary non-stressful crises based on HolmesRahe-Stress-Scale and avoid any couples getting systematic refractory diseases. The sample numbers were calculated by considering the safety factor $95 \%$ (1.96) and test power factor $80 \%$. The sampling was as available so that either all the couples were candidate for

using fertility assistance, who referred to the clinic for starting treatment process of fertility assistance, a preliminary interview has been done and as reading the profile, the Informed consent was taken from the eligible persons. After registering the landmarks, using level of coping strategies and stress level, anxiety and depression were evaluated for any couple by using self-report questionnaires.

Instruments

The coping strategies were evaluated by using the reviewed questionnaire of the cope revised [15] 32 items 8 domains of self-blame $(\mathrm{SB})$, self-focused rumination (SR), expressing emotion (EE), understanding emotion (UE), maintaining optimism (MO), goal replacement (GR), other blame (OB) and mental disengagement (MD) as the multiple choice Likert scale (1-4) including 1: at all, 2: unusual, 3: sometimes, 4: Internal reliability and repetition were studied after a guidance study on 15 eligible couples and its repetition was evaluated after 3 weeks. Internal reliability of the questionnaire with Cronbach's alpha 0.86 and Intra-Cluster correlation index 0.72 were confirmed. Analyzing the confirmed factor also showed that the 32 items questionnaire had a good construct validity for measuring men's coping strategies (CMIN/DF $=1.5, p=0.162)$ and for women $(C M I N / D F=1,0.582, p=0.241)$. The stress, anxiety and depression levels of the couples were evaluated by using a valid questionnaire DASS 21 as a self-report one.

Ethical considerations

The Regional Ethical Review Board in Isfahan University of Medical Sciences approved the study (IR.MUI.REC. 396703).

Analyzing data was done by using web application software SPSS software. Used statistical tests were including paired t test, multivariate linear regression. In using the linear regression, just those variables were entered the model which have a significant association with the coping strategies by using Pearson's coefficient of correlation (the results were not reported).

\section{Results}

Data analysis was done on 212 couples with $100 \%$ participation. The results showed that the mean (standard deviation) of infertility duration in the participants was 6.0 (4.3) years. In 107 (50.47\%) of the couples, the major reason for infertility was female factor and 80 $(37.74 \%)$ of them was male factor and for $25(11.79 \%)$ of the couples it had unexplained infertility. The results showed that age of the men and education level of the women are more than their partners, respectively (Table 1). The comparing of couples' coping strategies showed that women were using the of SB, OB, SR, and EE strategies more than their partners' and the men were using the MO strategy more than women. The mean of stress, anxiety and depression levels of women were significantly more than men. 
Table 1

Comparison of demographic characterizes and main variables between couples

\begin{tabular}{|c|c|c|c|}
\hline & \multicolumn{2}{|c|}{ Mean (SD) or number (\%) } & \multirow[t]{2}{*}{ Sig } \\
\hline & Women & Men & \\
\hline Number & 212 & 212 & \\
\hline Age & $32.2(4.8)$ & $36.6(5.0)$ & $<0.001$ \\
\hline Educational level (\%) & & & $<0.05$ \\
\hline Less than high school & $23(11.3)$ & $30(14.1)$ & $<0.001$ \\
\hline High school diploma & $157(74.1)$ & $161(76.0)$ & $<0.001$ \\
\hline University degree & $31(14.6)$ & $21(9.9)$ & $<0.001$ \\
\hline Coping strategies & & & $<0.001$ \\
\hline Self-blame & $8.3(3.4)$ & $7.1(3.2)$ & $<0.001$ \\
\hline Self-focused rumination & $10.4(3.9)$ & $8.5(3.5)$ & $<0.001$ \\
\hline Expressing emotion & $8.4(3.4)$ & $7.0(3.1)$ & $<0.001$ \\
\hline Understanding emotion & $6.8(2.9)$ & $5.6(2.5)$ & $<0.001$ \\
\hline Maintaining optimism & $10.8(3.3)$ & $12.2(3.8)$ & $<0.001$ \\
\hline Goal replacement & $10.2(3.5)$ & $10.8(3.3)$ & ns \\
\hline Other blame & $7.0(3.4)$ & $6.3(3.0)$ & $<0.001$ \\
\hline Mental disengagement & $10.1(3.1)$ & $10.3(3.0)$ & ns \\
\hline \multicolumn{4}{|l|}{ Psychological symptoms } \\
\hline Stress level & $14.0(5.4)$ & $9.0(4.4)$ & $<0.001$ \\
\hline Anxiety level & $9.9(5.4)$ & $5.5(3.4)$ & $<0.001$ \\
\hline Depression level & $10.7(6.7)$ & $6.6(4.7)$ & $<0.001$ \\
\hline
\end{tabular}

The results showed that the couples' coping strategies were related to their partners' coping strategies (Table 2). The relationship between the couples' coping strategies and women's psychological symptoms showed that, the stress level in women was related to using of the SR and OB coping strategies positively. Also, the women's depression level had a significant and inverse relationship with using GR coping strategies. The psychological symptoms in women were not related to their partners' coping strategies directly (Table 3). 
Table 2

The relation between Partner's coping strategies

\begin{tabular}{|c|c|c|c|c|c|c|c|c|}
\hline & \multicolumn{8}{|l|}{ Beta } \\
\hline & \multicolumn{8}{|c|}{ Coping Strategies } \\
\hline & \multicolumn{8}{|c|}{ Women's Coping Strategies } \\
\hline & $\begin{array}{l}\text { Self- } \\
\text { blame }\end{array}$ & $\begin{array}{l}\text { Self- } \\
\text { focused } \\
\text { rumination }\end{array}$ & $\begin{array}{l}\text { Expressing } \\
\text { emotion }\end{array}$ & $\begin{array}{l}\text { Understanding } \\
\text { emotion }\end{array}$ & $\begin{array}{l}\text { Maintaining } \\
\text { optimism }\end{array}$ & $\begin{array}{l}\text { Goal } \\
\text { replacement }\end{array}$ & $\begin{array}{l}\text { Other } \\
\text { blame }\end{array}$ & $\begin{array}{l}\text { Mental } \\
\text { disengagement }\end{array}$ \\
\hline Age & $-.15^{*}$ & $-.28^{\star \star \star}$ & $-.24^{\star \star}$ & $-.25^{\star \star}$ & .08 & .21 & -.11 & .04 \\
\hline $\begin{array}{l}\text { Educational } \\
\text { level }\end{array}$ & -.05 & $-.18^{\star *}$ & $-.17^{*}$ & -.05 & .02 & -.01 & -.04 & -.101 \\
\hline Duration of Inf. & $.25^{\star *}$ & .17 & .01 & .08 & -.02 & -.08 & .13 & .02 \\
\hline $\begin{array}{l}\text { Male factor } \\
\text { infertility }\end{array}$ & $-.12^{\star \star}$ & -.12 & .04 & $-.24^{\star *}$ & .07 & .13 & -.12 & .10 \\
\hline $\begin{array}{l}\text { Female factor } \\
\text { infertility }\end{array}$ & -.23 & .04 & -.14 & -.01 & .05 & .11 & .12 & .13 \\
\hline $\begin{array}{l}\text { Unexplained } \\
\text { infertility }\end{array}$ & .08 & .05 & .05 & -.06 & .01 & .01 & .06 & .01 \\
\hline Partners' CS & & & & & .07 & & & \\
\hline Self-blame & .16 & $.17^{*}$ & .04 & .05 & -.02 & .19 & $.37^{\star * \star}$ & $.21^{*}$ \\
\hline $\begin{array}{l}\text { Self-focused } \\
\text { rumination }\end{array}$ & .16 & .17 & .07 & .15 & -.17 & -.18 & -.13 & -.17 \\
\hline $\begin{array}{l}\text { Expressing } \\
\text { emotion }\end{array}$ & -.04 & -.08 & $.19^{*}$ & -.12 & -.15 & -.01 & .12 & -.10 \\
\hline $\begin{array}{l}\text { Understanding } \\
\text { emotion }\end{array}$ & .15 & .15 & .06 & $.20^{*}$ & -.10 & -.03 & -.03 & -.07 \\
\hline $\begin{array}{l}\text { Maintaining } \\
\text { optimism }\end{array}$ & .08 & .01 & .08 & .02 & .12 & .01 & .03 & -.02 \\
\hline $\begin{array}{l}\text { Goal } \\
\text { replacement }\end{array}$ & .04 & .12 & -.03 & -.05 & .13 & .13 & -.04 & -.10 \\
\hline Other blame & -.04 & -.05 & $-.21^{\star *}$ & -.06 & .01 & -.05 & .05 & $.23^{\star \star}$ \\
\hline \multirow[t]{2}{*}{$\begin{array}{l}\text { Mental } \\
\text { disengagement }\end{array}$} & -.04 & .10 & .05 & .11 & .08 & -.02 & -.06 & .09 \\
\hline & \multicolumn{8}{|c|}{ Men's coping Strategies } \\
\hline Age & .05 & -.01 & .07 & .12 & -.04 & .06 & .06 & -.01 \\
\hline $\begin{array}{l}\text { Educational } \\
\text { level }\end{array}$ & -.03 & -.08 & -.11 & -.01 & .08 & .06 & -.05 & -.07 \\
\hline Duration of Inf. & -.13 & -.07 & .01 & -.11 & -.11 & .03 & -.05 & -.03 \\
\hline $\begin{array}{l}\text { Male factor } \\
\text { infertility }\end{array}$ & .05 & .01 & .08 & $.18^{\star}$ & $.27^{\star \star}$ & $.22^{\star \star}$ & $.17^{\star}$ & .02 \\
\hline $\begin{array}{l}\text { Female factor } \\
\text { infertility }\end{array}$ & -.10 & -.08 & -.01 & .06 & .09 & .04 & -.01 & -.06 \\
\hline $\begin{array}{l}\text { Unexplained } \\
\text { infertility }\end{array}$ & -.06 & -.13 & -.03 & .12 & $-.14^{*}$ & -.14 & -.02 & $-.17^{*}$ \\
\hline
\end{tabular}

Abbreviation: CS: Copping strategies. ${ }^{*} p<0.05 ;{ }^{* *} p<.01 ;{ }^{* *} p<.001$ 


\begin{tabular}{|c|c|c|c|c|c|c|c|c|}
\hline & Beta & & & & & & & \\
\hline \multicolumn{9}{|l|}{ Partners' CS } \\
\hline Self-blame & .12 & .19 & -.01 & .06 & .09 & -.03 & .11 & -.10 \\
\hline $\begin{array}{l}\text { Self-focused } \\
\text { rumination }\end{array}$ & .16 & -.03 & .06 & .10 & .03 & $.23^{*}$ & .15 & $.20^{*}$ \\
\hline $\begin{array}{l}\text { Expressing } \\
\text { emotion }\end{array}$ & -.09 & .06 & $.21^{*}$ & -.01 & .08 & -.04 & $-.25^{\star \star}$ & .07 \\
\hline $\begin{array}{l}\text { Understanding } \\
\text { emotion }\end{array}$ & .05 & .04 & -.08 & .12 & -.02 & -.03 & .04 & .11 \\
\hline $\begin{array}{l}\text { Maintaining } \\
\text { optimism }\end{array}$ & .06 & -.11 & $-.18^{*}$ & -.15 & -.03 & .13 & .09 & .05 \\
\hline $\begin{array}{l}\text { Goal } \\
\text { replacement }\end{array}$ & -.02 & -.01 & .03 & .01 & .13 & .12 & -.15 & .02 \\
\hline Other blame & $.24^{* *}$ & .12 & .12 & -.04 & -.04 & -.01 & .11 & -.05 \\
\hline $\begin{array}{l}\text { Mental } \\
\text { disengagement }\end{array}$ & $.18^{*}$ & .19 & .05 & .09 & -.08 & -.13 & $.27^{\star \star \star}$ & .05 \\
\hline
\end{tabular}


Table 3

The relation between women's psychological symptoms and couples coping strategies

\begin{tabular}{|c|c|c|c|c|c|c|c|c|c|c|c|c|}
\hline & \multicolumn{12}{|c|}{ Women's Psychological Symptoms } \\
\hline & \multicolumn{4}{|c|}{ Stress level } & \multicolumn{4}{|c|}{ Anxiety level } & \multicolumn{4}{|c|}{ Depression level } \\
\hline & \multicolumn{4}{|c|}{$\mathrm{R}^{2}{ }_{\mathrm{Adj}}=.45 \mathrm{p}<.0001, \mathrm{~F}=8.54$} & \multicolumn{4}{|c|}{$\mathrm{R}^{2}{ }_{\mathrm{Adj}}=.32 \mathrm{p}<.0001, \mathrm{~F}=5.28$} & \multicolumn{4}{|c|}{$\mathrm{R}^{2}{ }_{\mathrm{Adj}}=.39 \mathrm{p}<.0001, \mathrm{~F}=6.79$} \\
\hline & Beta & sig & $\mathrm{Cl} 95 \%$ & & Beta & sig & $\mathrm{Cl} 95 \%$ & & Beta & sig & $\mathrm{Cl} 95 \%$ & \\
\hline Age & -.06 & ns & -.42 & .15 & -.13 & ns & -.53 & .04 & -.6 & ns & -.41 & .19 \\
\hline Education level & -.08 & ns & -1.82 & .48 & -.09 & ns & -1.92 & .40 & -.13 & ns & -2.32 & .11 \\
\hline Duration of Infertility & -.09 & ns & -3.04 & .49 & -.03 & ns & -2.18 & 1.37 & -.10 & ns & -3.23 & .49 \\
\hline Male factor infertility & -.15 & .03 & -7.10 & -.48 & -.6 & ns & -4.75 & 1.90 & -.12 & ns & -6.54 & .41 \\
\hline Female factor infertility & -.08 & ns & -4.84 & 1.06 & -.03 & ns & -3.66 & 2.27 & -.12 & ns & -6.45 & .25 \\
\hline Unexplained infertility & .01 & ns & -3.65 & 3.69 & -.01 & ns & -3.99 & 3.17 & -.01 & ns & -4.11 & 3.61 \\
\hline \multicolumn{13}{|l|}{ Womenls CS } \\
\hline Self-blame & -.04 & ns & -11.23 & 6.02 & .07 & ns & -5.09 & 12.22 & .08 & ns & -3.98 & 14.12 \\
\hline Self-focused rumination & .40 & $<.0001$ & 14.65 & 33.64 & .27 & .003 & 5.07 & 24.11 & .26 & .003 & 5.15 & 25.07 \\
\hline Expressing emotion & .01 & ns & -8.11 & 8.42 & .03 & ns & -8.14 & 8.45 & -.02 & ns & -9.75 & 7.57 \\
\hline Understanding emotion & .09 & ns & -2.55 & 11.72 & .07 & ns & -4.09 & 10.23 & .08 & ns & -3.398 & 11.57 \\
\hline Maintaining optimism & -.07 & ns & -14.85 & 4.61 & .02 & ns & -8.69 & 10.83 & -.06 & ns & -14.20 & 6.21 \\
\hline Goal replacement & -.11 & ns & -16.51 & 1.51 & -.09 & ns & -14.53 & 3.55 & -.16 & .04 & -19.51 & -.60 \\
\hline Other blame & .18 & .006 & 2.84 & 16.85 & .19 & .007 & 2.66 & 16.72 & .18 & .008 & 2.66 & 17.35 \\
\hline Mental disengagement & -.05 & ns & -13.55 & 6.63 & .02 & ns & -8.97 & 11.27 & .01 & ns & -9.61 & 9.55 \\
\hline \multicolumn{13}{|l|}{ Partner's CS } \\
\hline Self-blame & .02 & ns & -8.12 & 10.49 & -.03 & ns & -10.94 & 7.73 & -.01 & ns & -9.81 & 9.67 \\
\hline Self-focused rumination & .02 & ns & -8.14 & 9.31 & .07 & ns & -5.88 & 11.63 & .03 & ns & -7.54 & 10.75 \\
\hline Expressing emotion & -.08 & ns & -11.28 & 3.08 & -.09 & ns & -11.44 & 2.97 & -.09 & ns & -12.19 & 2.86 \\
\hline Understanding emotion & .03 & ns & -5.10 & 7.47 & -.04 & ns & -7.82 & 4.80 & .02 & ns & -5.81 & 7.37 \\
\hline Maintaining optimism & -.02 & ns & -12.46 & 9.55 & -.03 & ns & -13.35 & 8.74 & -.04 & ns & -14.68 & 8.41 \\
\hline Goal replacement & .06 & ns & -6.19 & 13.04 & .02 & ns & -8.67 & 10.63 & .04 & ns & -7.45 & 12.72 \\
\hline
\end{tabular}

\section{Conclusions}

The aim of this study was to recognize the interrelationships of the coping strategies and women's psychological symptoms indices in couples who were under treatment of fertility assistance methods. Based on this, the relationship between the using of couples' coping strategies and relationship between the using of couples' coping strategies with women's stress, anxiety and depression levels has been evaluated. The results showed that the couples' coping strategies are interacted and the women's stress, anxiety and depression levels of the women are raised by the using of the self-focused rumination and other blame strategies. These results suggest that the psychological symptoms in women are affected by interactions between couples' coping strategies toward infertility.

The findings indicated that women use maladaptive coping strategies more than men. They also suffer from stress, anxiety and depression more than men. Women are under the pressure of society for infertility more than men [16-18]. And it can reduce their 
ability in controlling the conditions. It can be effective for their using of coping strategies, too.

The results showed an interrelation of coping strategies in the infertile couples with each other. The results of the research showed that men's using of SB strategy was in a circular relationship with women's using of OB and MD strategies. So that the men's using of SB strategy depended on women's using of OB strategy and the women whose husbands use SB strategy, OB more. Also, avoidance reactions of women were accompanied by more use of blame strategy by men and women's using of this strategy depended on using SB strategy level by men.

This relation shows that women's addressees for blaming the others are their husbands and the men facing this strategy and avoidance strategy assign the infertility problems to themselves and blame themselves more. This finding as well as the others' findings representing dependence of women's using level of SR strategy on men's using of SB strategy, showed the importance of bilateral relationships between infertile couples in using adaptive coping strategies.

Despite the self-blame strategy which men and women use maladaptive strategies against; another finding shows that using EE coping strategy by the couples has interrelationship with each other. This finding, as one of the couples shares his/ her feelings about infertility, shows the other will present his/ her feelings. Moderating role of the couples' relationship quality with each other has been known in expressing bilateral feelings [11] and this research shows that expressing feelings by the women makes the men share their own feelings more and use the maladaptive strategies less like other blame ones, too.

The negative psychological symptoms of women after use of SR strategy may be accompanied by men's use of the same strategy and so that; the men attempt to take his thoughts away from infertility by using the strategy of GR strategy and avoidance.

Another finding showed that some types of coping strategies are determinant factors for stress, anxiety and depression changes in women. So that the results showed that negative psychological symptoms in women were increased by using the coping strategies of $\mathrm{SR}$ and $\mathrm{OB}$. This finding is also the same as Kraaij et al report who showed using this strategy is accompanied by increasing depression level and anxiety [19]. Another study has also shown that using maladaptive coping strategies is accompanied by destroying the psychological health of infertile couples [20].

The inverse relation of women's using of GR strategy with negative psychological symptoms and positive relation of men's using of MD strategy with their anxiety level are the other findings of this research. These results are in direction of the other researches reports which have shown the positive effects of using this strategy in faced with the crisis in men and women [21, 22]. Also, the inverse effects of using avoidance strategies on psychological health of infertile couples have already been reported [12, 23], but despite these reports, in the present research there was no significant relationship between women's using of avoidance strategy and their psychological health indices. However, there are also some studies which show that using the avoidance strategy will balance psychological reactions in the infertile couples [12, 24]. Anyway, it must be considered that the study target population was the couples under fertile assistance treatment and their entering into treatment process requires attempting for resolving infertility problems and persons, who often use the avoidance coping strategy, may try to treat the infertility less.

Although in this research, direct relationship between psychological health conditions and couples' coping strategies hasn't been observed, the interaction between the couples' coping strategies may mediate the effect of the men's coping strategies on their partner's psychological health. These results consolidate the importance of increasing the skill for using coping strategies in the infertile couples.

Although this study has shown interrelationships between the couples' coping strategies, its results must interpret according to the research limitations. The first research limitation was its cross sectional nature. Since in this research, the psychological conditions and quality of marital relationships and personal features which can impress their coping strategy need to be studied in future. Also, the figure process has effect on couples' relationships, concluding from the research findings are accompanied by limitation. Therefore, because the study has been done on infertile couples under fertility assistance treatment, generalizing the results to the infertile couples who aren't under fertility assistance treatments will be limited.

\section{Conclusion}

The results of this study show that the coping strategies of infertile couples relate to each other but in this interaction, the type of strategy used for men and women isn't necessarily the same. The psychological health of the women depend on the use of these 
strategies, too. So, it's necessary to design counseling plans for optimal use of strategic approaches in order to promote psychological health of the women under the fertility assistance.

\section{Abbreviations}

\section{SB}

Self-blame, SR:Self-focused rumination, EE:Expressing emotion, UE:Understanding emotion, MO:Maintaining optimism, GR:Goal replacement, OB:Other blame, MD:Mental disengagement, DASS:Depression Anxiety Stress Scales, AMOS:Analysis of a moment structures

SD

standard deviation; sig:significance; ns:not significant, G:group

\section{Declarations}

\section{Authors' contributions}

AK: Project development, data collection supervising, acquisition of analysis, interpretation of data, and editing the manuscript. MT: Project development, data collection, manuscript writing. MA: acquisition of analysis, interpretation of data, and editing the manuscript.

\section{Author details}

${ }^{1}$ Reproductive Health Department, Nursing and Midwifery Health Care Research Center, Isfahan University of Medical Sciences, Isfahan, Iran. ${ }^{2}$ Student Research Committee, School of Nursing and Midwifery, Isfahan University of Medical Sciences, Isfahan, Iran. ${ }^{3}$ Midwifery Department, Nursing and Midwifery Health Care Research Center, Isfahan University of Medical Sciences, Isfahan, Iran.

\section{Acknowledgments}

We would like to thank Isfahan University of Medical Sciences for financial support.

\section{Competing interests}

The authors declare that they have no conflict of interest.

\section{Availability of data and materials}

The datasets used during the current study are available from the corresponding author on reasonable request.

\section{Consent for publication}

Not applicable

\section{Ethics approval and consent to participate}

All procedures performed in participants were in accordance with the ethical standards of the Isfahan University of Medical Sciences (IR.MUI.REC. 394349) and informed written consent was obtained from all participants.

\section{Funding}

This study was supported by the Isfahan University of Medical Sciences (Grant number: 394349) 


\section{References}

1. de Kok BC. Automatically you become a polygamist': 'culture' and 'norms' as resources for normalization and managing accountability in talk about responses to infertility. Health (London). 2009;13(2): 197-217. doi:10.1177/1363459308099684.

2. Ergin RN, Polat A. Social stigma and familial attitudes related to infertility. Turk J Obstet Gynecol. 2018; 15(1): 46-9. doi:10.4274/tjod.04307.

3. Stellar C, Garcia-Moreno C, Temmerman M, van der Poel S. A systematic review and narrative report of the relationship between infertility, subfertility, and intimate partner violence. International journal of gynaecology and obstetrics: the official organ of the International Federation of Gynaecology and Obstetrics. 2016; 133(1): 3-8. doi:10.1016/j.ijgo.2015.08.012.

4. Turnbull B, Graham ML, Taket AR. Pronatalism and Social Exclusion in Australian Society: Experiences of Women in their Reproductive Years with No Children. Gend Issues. 2017; 34(4): 333-54. doi:10.1007/s12147-016-9176-3

5. Cheng CY, Stevenson EL, Yang CT, Liou SR. Stress and quality of life for Taiwanese women who underwent infertility treatment. J Obstet Gynecol Neonatal Nurs. 2018; 47(4): 498-508.

6. Dierickx S, Rahbari L, Longman C, Jaiteh F, Coene G. 'I am always crying on the inside': a qualitative study on the implications of infertility on women's lives in urban Gambia. Reprod Health. 2018; 15: 11. doi:10.1186/s12978-018-0596-2.

7. Skvirsky V, Taubman-Ben-Ari O, Ben Shlomo S, Azuri J, Horowitz E. Contributors to women's perceived stress at the start of assisted reproductive technology. J Psychol. 2018; 153(1):1-14. doi:10.1080/00223980.2018.1471037.

8. Kurzawa R, Kuczynski W, Pawelczyk L, Wolczynski S. Cost-effectiveness of IVF infertility treatment in different legislative settings. Ginekol Pol. 2010; 81(2): 125-30. doi:10.1097/yco.0000000000000091.

9. Rooney KL, Domar AD. The relationship between stress and infertility. Dialogues Clin Neurosci. 2018; 20(1): 41.

10. Gourounti K, Anagnostopoulos F, Potamianos G, Lykeridou K, Schmidt L, Vaslamatzis G. Perception of control, coping and psychological stress of infertile women undergoing IVF. Reprod Biomed Online. 2012;24(6): 670-9.

doi:10.1016/j.rbmo.2012.03.002.

11. Yazdani F, Kazemi A, Fooladi MM, Samani HRO. The relations between marital quality, social support, social acceptance and coping strategies among the infertile Iranian couples. Eur J Obstet Gynecol Reprod Biol. 2016;200: 58-62. doi:10.1016/j.ejogrb.2016.02.034.

12. Li J, Liu BT, Li M. Coping with infertility: a transcultural perspective. Curr Opin Psychiatr. 2014;27(5):320-5. doi:10.1097/yco.0000000000000091.

13. Alosaimi FD, Bukhari M, Altuwirqi M, Habous M, Madbouly K, Abotalib Z, Binsaleh S. Gender differences in perception of psychosocial distress and coping mechanisms among infertile men and women in Saudi Arabia. Hum Fertil. 2017;20(1):55-63.

14. Kaya Z, Oskay U. Stigma, hopelessness and coping experiences of Turkish women with infertility. Journal of Reproductive and Infant Psychology. 2019; [in press]. doi:10.1080/02646838.2019.1650904.

15. Zuckerman M, Gagne M. The COPE revised: Proposing a 5-factor model of coping strategies. J Res Pers. 2003;37(3):169-204. doi:10.1016/s0092-6566(02)00563-9.

16. Ross R, Hess RF. Social Pressure for Pregnancy Scale: Its Development, Psychometric Properties, and Potential Contributions to Infertility and Depression Research. J Nurs Meas. 2019;27(1):5-15. doi:10.1891/1061-3749.27.1.5.

17. Gameiro S, Refaie E, de Guevara BB, Payson A. Women from diverse minority ethnic or religious backgrounds desire more infertility education and more culturally and personally sensitive fertility care. Hum Reprod. 2019;34(9):1735-1745. doi:10.1093/humrep/dez156.

18. Ogawa M, Takamatsu K, Horiguchi F. Evaluation of factors associated with the anxiety and depression of female infertility patients. Biopsychosoc Med. 2011;5(1):15. doi:10.1186/1751-0759-5-15.

19. Kraaij V, Garnefski N, Schroevers MJ, Weijmer J, Helmerhorst F. Cognitive coping, goal Adjustment, and depressive and anxiety symptoms in people undergoing infertility treatment: a prospective study. J Health Psychol. 2010;15(6):876-886. doi:10.1177/1359105309357251.

20. Driscoll MA, Davis MC, Aiken LS, Yeung EW, Sterling EW, Vanderhoof V, Calis KA, Popat V, Covington SN, Nelson LM. Psychosocial vulnerability, resilience resources, and coping with infertility: A longitudinal model of adjustment to primary ovarian insufficiency. Ann Behav Med. 2016;50(2):272-284. doi:10.1007/s12160-015-9750-z. 
21. Chaves C, Canavarro MC, Moura-Ramos M. The Role of Dyadic Coping on the Marital and Emotional Adjustment of Couples with Infertility. Family Process. 2019;58(2):509-523. doi:10.1111/famp.12364.

22. Molgora S, Fenaroli V, Acquati C, De Donno A, Baldini MP, Saita E. Examining the Role of Dyadic Coping on the Marital Adjustment of Couples Undergoing Assisted Reproductive Technology (ART). Frontiers in Psychology. 2019;19:415. doi:10.3389/fpsyg.2019.00415.

23. Casu G, Zaia V, Martins MDF, Barbosa CP, Gremigni P. A Dyadic Mediation Study on Social Support, Coping, and Stress Among Couples Starting Fertility Treatment. Journal of Family Psychology. 2019;33(3):315-326. doi:10.1037/fam0000502.

24. Mohammadi M, Samani RO, Navid B, Maroufizadeh S, Sabeti S. Coping strategy in infertile couples undergoing assisted reproduction treatment. Middle East Fertility Society Journal. 2018;23(4):482-485. doi:10.1016/j.mefs.2018.07.004. 